\title{
O ATENDIMENTO DE CRIANÇAS E ADOLESCENTES COM DEFICIÊNCIA VÍTIMAS DE VIOLÊNCIAS NO SISTEMA DE GARANTIA DE DIREITOS
}

\author{
Ana Radig Denne Lobão Morais ${ }^{1}$ \\ José Claudio Monteiro de Brito Filho ${ }^{2}$
}

\section{RESUMO:}

O presente artigo almeja apresentar a criança e o adolescente com deficiência como sujeitos de direitos que necessitam de um atendimento que leve em consideração as necessidades e limitações específicas de cada deficiência. Consideramos para esta análise que a Lei $\mathrm{n}^{\mathbf{o}}$ 13.431/2017 não abrange vítimas com deficiência, o que só ocorre no Decreto que a regulamenta e ainda assim, de forma insuficiente. Como norma complementar à Lei citada, apresentamos a Resolução Conjunta $\mathrm{n}^{\circ} 01$ do CONANDA e do CONADE, em uma interpretação que almeja promover o direito ao acesso à justiça destas vítimas. Utilizaremos a metodologia teórica.

Palavras-Chave: Violência; criança e adolescente com deficiência; depoimento especial; escuta especializada; direitos humanos.

\section{THE CARE OF DISABLED CHILDREN AND ADOLESCENTS VICTIMS OF VIOLENCE AT THE SYSTEM FOR THE GUARANTEE OF CHILDREN AND ADOLESCENTS' RIGHTS}

\begin{abstract}
:
This article aims to present disabled children and adolescents as individuals with rights who need an assistance that takes into account the specific needs and limitations of each disability. For this analysis, we considered that Law No. 13,431/2008 does not embrace disabled victims: it only takes place in the Decree which regulates it, but insufficiently, even so. As a complementary standard to the mentioned Law, we present the Joint Motion no. 01 of CONANDA and CONADE, in an interpretation that aims to promote to access to justice by these victims. We will use theoretical methodology.
\end{abstract}

Keywords: Violence; disabled children and adolescents; special testimony; specialized listening; human rights.

\section{INTRODUÇÃO}

\footnotetext{
${ }^{1}$ Mestranda em Direito, Políticas Públicas e Desenvolvimento Regional pelo Centro Universitário do Estado do Pará - CESUPA. E-mail: anaradig@yahoo.com.br.

2 Doutor em Direito das Relações Sociais (PUC/SP); professor do Programa de Pós Graduação e do Curso de Graduação em Direito do Centro Universitário do Estado do Pará - CESUPA. E-mail: jclaudiobritofilho@gmail.com.
} 
O presente estudo, que tem por tema: o atendimento de crianças e adolescentes com deficiência vítimas de violências no sistema de garantia de direitos, almeja analisar os dispositivos normativos que disciplinam este atendimento, bem como investigar se estes instrumentos mostram-se suficientes para a garantia e efetivação do direito ao acesso à justiça com absoluta prioridade e observando a condição de pessoas em condição peculiar de desenvolvimento e com deficiência.

Não pretendemos exaurir a discussão a respeito do tema, e sim chamar a atenção para os avanços alcançados mediante a Legislação e Resoluções realizadas tanto pelo Conselho Nacional de Justiça (230, de 22 de junho de 2016) quanto pelo Conselho Nacional dos Direitos da Criança e do Adolescente e Conselho Nacional dos Direitos da Pessoa com Deficiência (Resolução Conjunta $n^{\circ}$ 01, de 24 de outubro de 2018).

Para alcançar este objetivo, não nos dedicaremos à análise aprofundada da Convenção Internacional sobre os Direitos das Pessoas com Deficiência e seu Protocolo Facultativo e da Lei Brasileira de Inclusão da Pessoa com Deficiência, utilizando-os apenas em ocasiões específicas, para corroborar com o que será defendido no trabalho.

O problema de pesquisa deste trabalho que será respondido ao final da análise é: a criança e o adolescente com deficiência estão inseridos nas normas protetivas que visam estruturar o atendimento no sistema de garantia de direitos?

Para alcançar a resposta ao problema de pesquisa escolhido, teremos por objetivo geral a análise da trajetória da garantia e efetivação do direito de crianças e adolescentes vítimas à participação no sistema de garantia de direitos de maneira adequada ao seu grau de desenvolvimento (físico, cognitivo, emocional, etário) e como objetivos específicos avaliaremos e demonstraremos como se encontram as normas específicas sobre crianças e adolescentes com deficiência vítimas de violência, tanto na Legislação quanto mediante Resoluções em vigor.

As principais referências teóricas utilizadas são: a doutrina sobre o depoimento especial, aqui representada pela obra de Luciane Potter, intitulada "Depoimento especial de crianças e adolescentes: quando a interdisciplinariedade aproxima olhares" e a obra de Martha Nussbaum, intitulada "Fronteiras da Justiça".

A metodologia utilizada é predominantemente teórica e o presente artigo apresenta a seguinte estrutura: no segundo item, discorreremos a respeito da trajetória percorrida para que o direito conferido à crianças e adolescentes vítimas de violência a participar de maneira 
adequada no sistema de garantia de direitos, levando em consideração o grau de desenvolvimento destas vítimas e a natureza da violência sofrida.

Para alcançar os objetivos deste item, analisaremos os seguintes dispositivos normativos: Convenção sobre os Direitos da Criança; Constituição da República de 1988; Estatuto da Criança e do Adolescente; Resolução no 33 de 23 de novembro de 2010 do Conselho nacional de Justiça; Resolução n ${ }^{\circ} 10$ de 29 de junho de 2010 do Conselho Federal de Psicologia; Lei n ${ }^{\circ}$ 13.431/2017 e Decreto no 9.603 de 10 de dezembro de 2018.

No item 3 analisaremos a Lei $n^{\circ} 13.431 / 2017$ e o Decreto que a regulamenta, almejando abordar criticamente a sua aplicabilidade e adequação às necessidades específicas de crianças e adolescentes com deficiência, bem como a Resolução Conjunta entre o CONANDA e o CONADE citada acima e, por fim, as considerações finais.

2 TRAJETÓRIA DA GARANTIA E EFETIVAÇÃO DO DIREITO DA CRIANÇA E ADOLESCENTE VÍTIMA A PARTICIPAR DE MANEIRA ADEQUADA NO SISTEMA DE GARANTIA DE DIREITOS

A garantia e efetivação de direitos de crianças e adolescentes percorreu e ainda percorre um caminho árduo e lento, no qual no Brasil, a Constituição da República em vigor foi responsável pela mudança de paradigma no que tange às normas direcionadas a estes sujeitos de direitos.

Andréa Rodrigues Amin, em livro coordenado por Kátia Regina Maciel, ao discorrer sobre esta mudança de paradigma, afirma que, com a Constituição da República em vigor:

\footnotetext{
implanta-se a Doutrina da Proteção Integral, com caráter de política pública. Crianças e adolescentes deixam de ser objeto de proteção assistencial e passam a titulares de direitos subjetivos. Para assegurá-los é estabelecido um sistema de garantia de direitos, que se materializa no Município, a quem cabe estabelecer a política de atendimento dos direitos da criança e do adolescente (MACIEL, p. 57, 2018).
}

Esta mudança, pautada na dignidade da pessoa humana trouxe a doutrina da proteção integral direcionada a crianças e adolescentes em seus artigos 227 e 228, disciplinando a corresponsabilidade entre a família, o Estado e a comunidade em geral na proteção e promoção de direitos daqueles que, a partir de então, passaram a ser tratados como sujeitos de direitos pela legislação pátria. 
Esta doutrina foi aperfeiçoada pala Lei no 8.069 de 1990 (que dispõe sobre o Estatuto da Criança e do Adolescente e dá outras providências) dispositivo legal que afirma que estes sujeitos de direitos possuem todos os direitos fundamentais inseridos na Carta Magna de forma prioritária. Porém, para que a criança e o adolescente tenham alcançado este status de sujeitos de direitos e progressivamente alcançassem direitos específicos e prioritários, foi percorrido um longo caminho de reconhecimento, garantia e efetivação de direitos.

O marco inicial da análise da garantia do direito à manifestação de crianças e adolescentes em processos judiciais ou administrativos que tenham relação aos seus interesses, no que tange ao Brasil, situa-se no campo do Direito Internacional dos Direitos Humanos, com a promulgação da Convenção sobre os Direitos da Criança. A Convenção sobre os Direitos da Criança foi adotada em Assembleia Geral das Nações Unidas em 20 de novembro de 1989 e entrou em vigor internacional em 02 (dois) de setembro de 1990.

De acordo com o endereço eletrônico do Unicef Brasil ${ }^{3}$, a Convenção em comento foi ratificada por 196 países, de forma que no Brasil foi aprovada pelo Congresso Nacional por meio do Decreto Legislativo $\mathrm{n}^{\mathbf{0}} 28$, de 14 de setembro de 1990 e promulgada pelo Presidente da República pelo Decreto no 99.710 de 21 de novembro de 1990 que em seu artigo 12 - 1 afirma que "os Estados Partes devem assegurar à criança (...) o direito de expressar suas opiniões livremente sobre todos os assuntos relacionados a ela, e tais opiniões devem ser consideradas em função da idade e da maturidade da criança" (Convenção sobre os Direitos da Criança, art. 12 - 1).

Este dispositivo torna-se pertinente a este estudo pelo fato de reconhecer à criança o direito de expressar suas opiniões, o que significa a valorização da fala destes sujeitos de direitos, de forma que são as condições proporcionadas no momento desta fala o objeto de análise do presente estudo. No mesmo sentido, o artigo em comento, em sua segunda parte, reitera o direito à fala direcionado à criança, condicionando o exercício deste direito às regras do ordenamento jurídico pátrio dos países que ratificarem a Convenção.

Ressalta-se que a promulgação da Convenção sobre os Direitos da Criança, apesar de garantir a crianças e adolescentes o direito de falar e de ser ouvido em processos judiciais e administrativos não efetivou tais direitos no Brasil.

Apresentamos este ponto de vista e afirmamos esta falta de alcance do objetivo por considerarmos que este direito só será efetivado quando for exercido de forma adequada ao

\footnotetext{
${ }^{3}$ Para mais informações sobre, acessar: https://www.unicef.org/brazil/pt/resources_10120.html.
} 
nível de desenvolvimento em todos os sentidos (físico, cognitivo, emocional, dentre outros que irão depender de casos específicos), incluindo também as crianças e adolescentes com deficiência, de forma que se garanta este direito sem causar danos ao depoente/testemunha.

Portanto, consideramos que a abordagem feita à crianças e adolescentes que depõe em Juízo e que são atendidos pelos outros órgãos do sistema de garantias de direitos na condição de vítimas de violência (que pode ser física, psicológica, sexual ou institucional) ou que se encontram em meio a uma disputa judicial por sua guarda, por exemplo, necessita levar em consideração a condição peculiar de ser humano em desenvolvimento destas crianças ou adolescentes, o que inclui a atenção às suas particularidades e limitações e, além disso, adaptar-se às necessidades específicas de crianças e adolescentes com deficiência.

Não é coerente e tampouco está em consonância com a doutrina da proteção integral que uma criança, em decorrência do seu estágio de desenvolvimento físico e cognitivo, realize um depoimento utilizando os mesmos meios e instrumentos que um adulto. $\mathrm{O}$ medo, a vergonha e o constrangimento precisam ser compreendidos. Também merece destaque a preocupação no que tange à compreensão do tipo e grau de violência sofrida.

Portanto, este contato entre os profissionais que trabalham no Sistema de Justiça e a vítima deve ocorrer de forma humanizada, compreensiva e impreterivelmente por profissionais capacitados para este tipo específico de demanda.

Ainda sobre a necessidade de um tratamento adequado, o ponto referente à qualidade da prova produzida no Judiciário mostra-se uma preocupação relevante, pois no procedimento tradicional não se possibilita uma tomada de depoimento eficaz, dado que caso a inquirição não seja feita de forma coerente com o estágio de desenvolvimento da vítima, estas não oferecerão respostas e declarações coerentes, o que pode levar à desvalorização e menosprezo do depoimento da criança, o que desqualifica o depoimento.

Neste contexto, com o escopo de implementar um procedimento capaz de evitar a ocorrência da revitimização destas vítimas, em 2003 foi implantado na $2^{\circ}$ Vara da Infância e Juventude de Porto Alegre o projeto Depoimento Sem Dano ${ }^{4}$, através do Magistrado José Antônio Daltoé Cezar, que, ao sentir a necessidade da existência de um ambiente adequado, bem como a atuação multidisciplinar de profissionais no atendimento às crianças e adolescentes vítimas de violência sexual, adaptou as experiências bem sucedidas de outros

\footnotetext{
${ }^{4}$ Para mais informações sobre o Projeto Depoimento sem Dano, acessar: http://jij.tjrs.jus.br/cij.php?pagina=cijdepoimento-especial.
} 
países na reformulação do procedimento concernente à tomada de depoimentos de crianças e adolescentes vítimas ou testemunhas de violência sexual, passando, a partir de então, a utilizar tal procedimento.

O projeto "Depoimento Sem Dano" teve por objetivo retirar crianças e adolescentes vítimas ou testemunhas de abuso sexual do ambiente das salas de audiência tradicional, realizando a oitiva em local que fosse especialmente projetado para o momento de oitiva dessas vítimas ou testemunhas infanto-juvenis, local este que respeite as particularidades de desenvolvimento psicológicos e físicos dessas vítimas e a situação delicada e difícil que infelizmente vivenciam.

Este projeto inicial objetivava a criação de um ambiente não-revitimizante e a adoção de posturas e práticas que tratem a criança e o adolescente considerando que eles são sujeitos de direitos e não meros objetos para a produção de provas.

As práticas da metodologia Depoimento sem Dano foram adaptadas à realidade de diversas comarcas do país, porém, algumas dificuldades foram enfrentadas pelos Juízes que compreendiam a necessidade de um procedimento adequado para a oitiva destas vítimas: a falta de recursos direcionados para a montagem de salas diferenciadas e a contundente oposição do Conselho Federal de Psicologia à realização da oitiva de crianças e adolescentes, em sede judicial, nos moldes da metodologia Depoimento sem Dano.

O Conselho Federal de Psicologia foi resistente à implantação de meios não tradicionais de inquirição, nos moldes apresentado acima, e editou a Resolução $\mathrm{n}^{\circ} 10$, datada de 29 de junho de 2010, na qual dentre outras providências e regulamentações, proibiu que os profissionais da psicologia atuassem nas inquirições de crianças e adolescentes em situação de violência.

Esta Resolução instituiu a regulamentação da Escuta Psicológica de crianças e adolescentes envolvidos em situações de violência, na rede de proteção e em seu último item determina que "é vedado ao psicólogo o papel de inquiridor no atendimento de crianças e adolescentes em situação de violência".

Até a ocasião da entrega deste trabalho, a Resolução no 10 de 2010 do Conselho Federal de Psicologia está suspensa em todo o território nacional em virtude da decisão do Juízo da $28^{\text {a }}$ Vara Federal do Rio de Janeiro, que deferiu o pedido de antecipação da tutela nos autos da Ação Civil Pública no 2012.51.01.008692-4 (sob o nº 0008692-96.2012.4.02.5101 no 
Cadastro Unificado do Conselho Nacional de Justiça) ajuizada pelo Estado do Rio de Janeiro, pelo Ministério Público Federal e pelo Ministério Público do Estado do Rio de Janeiro ${ }^{5}$.

Completamente oposta à Resolução no 10 de 2010 do Conselho Federal de Psicologia é a Resolução n 33, de 23 de novembro de 2010 do Conselho Nacional de Justiça, que recomendou aos tribunais a criação de serviços especializados para a escuta de crianças e adolescentes vítimas ou testemunhas de violência nos processos judiciais e relaciona estes serviços especializados ao Depoimento especial.

O denominado Depoimento Especial na referida Resolução possui os mesmos procedimentos do Depoimento sem Dano apresentado anteriormente neste estudo. Este procedimento consiste, em linhas gerais: na criação de sala separada da sala de audiências; comunicação por meio de pontos de áudio e vídeo e o procedimento de inquirição abarca primeiramente o acolhimento do depoente e em seguida a tomada do depoimento (Resolução $n^{\circ} 33$ do Conselho Nacional de Justiça).

A partir de então, a utilização das metodologias utilizadas no Depoimento sem dano/Depoimento Especial tornou-se cada vez mais conhecida pelos juízes, advogados e demais profissionais que atuam na área, e apesar da falta de obrigatoriedade se passou a realizar treinamentos específicos para a atuação da equipe multidisciplinar do Poder Judiciário para a utilização de formas alternativas de inquirição de crianças e adolescentes vítimas de violência.

Com o aumento do conhecimento sobre o Depoimento Especial por parte dos profissionais que atuam diretamente com crianças e adolescentes vítimas de violência e o aumento da pesquisa científica na área, o tema tornou-se pauta no Legislativo com o objetivo de regulamentar a forma de aplicação do Depoimento Especial e neste sentido, em 04 de abril de 2017 foi sancionada a Lei $n^{\circ} 13.431$ que estabelece o sistema de garantia de direitos da criança e do adolescente vítima ou testemunha de violência.

A referida Lei é o último passo alcançado no sentido de garantia de direitos de crianças e adolescentes vítimas de violência, complementada pelo Decreto $n^{\circ}$ 9.063, de 10 de dezembro de 2018, e inclui na sua proteção crianças e adolescentes testemunhas de violência, com a percepção de que tanto as vítimas quanto as testemunhas de violência precisam ter a sua disposição tratamento especial.

\footnotetext{
5 Informações sobre a Ação Civil Pública $\mathrm{n}^{\circ}$ 0008692-96.2012.4.02.5101 (2012.51.01.008692-4) em: https://juristas.com.br/wp-content/uploads /2017/03/00086929620124025101_540474.pdf
} 
Nesta perspectiva, a Lei $n^{\circ} 13.431 / 2017$ enumera no artigo $4^{\circ}$ as formas de violência contra a criança e o adolescente, quais sejam: violência física; violência psicológica; violência sexual e violência institucional. Esta última forma de violência citada merece destaque, pois refere-se àquela praticada por instituição pública ou conveniada, inclusive quando gerar revitimização.

Complementar à elucidação a respeito da violência institucional e em consonância com o escopo da lei, que é a proteção de crianças e adolescentes vítimas ou testemunhas de violência, no artigo $7^{\circ}$ dispõe sobre a escuta especializada e no $8^{\circ}$ sobre o depoimento especial. Ambos fazem parte do mesmo procedimento, porém, em fases distintas. A escuta especializada é realizada perante órgãos do sistema de proteção, no qual é realizada entrevista sobre situação de violência. Já o depoimento especial é realizado perante autoridade policial ou judiciária, sendo, portanto, um procedimento de oitiva.

Ambos os procedimentos apresentados acima almejam a redução de danos causados pela revelação da violência sofrida e pelas possíveis intervenções inadequadas por parte dos órgãos da rede de proteção, da polícia ou do poder judiciário. Assim, o dispositivo legal em questão garante procedimentos específicos e obrigatórios nos casos de atendimento de crianças e adolescentes vítimas ou testemunhas de violência e dispõe sobre a violência institucional.

Como citado acima, o Decreto $n^{\circ} 9.603$ de 10 de dezembro de 2018 é o último ato normativo que dispõe sobre a defesa de crianças e adolescentes vítimas ou testemunhas de violência. Este Decreto regulamenta a implementação da Lei no 13.431/2017, estabelecendo as diretrizes para a criação do sistema de garantias de direitos da criança e do adolescente vítimas ou testemunha de violência e entrou em vigor na data de sua publicação, que ocorreu no da 11 de dezembro de 2018.

Na próxima sessão, analisaremos a criança e o adolescente com deficiência como sujeitos de direitos que dependem de disponibilização de condições especiais (tanto de acessibilidade quanto no que tange à comunicação direcionada à revelação de violências sofridas até o momento da inquirição mediante a escuta especializada e o depoimento especial), a depender de cada deficiência, para que possam efetivamente ter acesso à justiça mediante o acesso ao sistema de garantias de direitos, incluindo o poder judiciário. 
3 A CRIANÇA E O ADOLESCENTE COM DEFICIÊNCIA NO SISTEMA DE GARANTIA DE DIREITOS: NECESSIDADES PARA ALÉM DAS DESTINADAS ÀS VÍTIMAS SEM DEFICIÊNCIA.

Como demonstrado no item anterior, a garantia dos direitos de crianças e adolescentes, no que tange à participação ativa e de maneira adequada ao grau de desenvolvimento destas vítimas no sistema de garantia de direitos, foi alcançada com a entrada em vigor da Lei $\mathrm{n}^{\circ}$ $13.431 / 2017$.

Neste item do artigo, afirmaremos que crianças e adolescentes com deficiência necessitam de atenção e cuidados específicos nos procedimentos realizados durantes a Escuta Especializada e o Depoimento Especial, reiterando que ambos os procedimentos foram introduzidos no arcabouço jurídico pátrio mediante a Lei 13.431/2017.

Sobre a invisibilização de crianças com deficiência no que tange ao acesso à justiça, Martha Nussbaum, ao trabalhar a ausência de pessoas com deficiência nos contratos sociais que determinam quais são os princípios de justiça que irão reger a comunidade, afirma que a ausência desta parcela da comunidade dos processos de decisão e representação é histórica, asseverando que:

\begin{abstract}
Até bem pouco tempo, na maioria das sociedades modernas, essas pessoas não eram sequer incluídas na sociedade. Eram excluídas e estigmatizadas; não havia movimento político para incluí-las. Principalmente pessoas com impedimentos mentais graves não tinham nem mesmo acesso à educação. Elas eram escondidas em instituições ou abandonadas à morte, por negligência; jamais foram consideradas parte do universo público (NUSSBAUM, 2013, p. 19).
\end{abstract}

A Escuta especializada e o Depoimento Especial, nos termos da lei em comento, são procedimentos que almejam diminuir a revitimização, sendo que esta pode ocorrer em virtude das inúmeras intervenções que objetivam a produção de provas, o que faz com que a vítima reviva a violência sofrida falando a vários profissionais e em locais diferentes, e evitar a violência institucional, sendo conceituada pelo Decreto ${ }^{\circ} 9.603$ de 10 de dezembro de 2018, artigo $5^{\circ}$, II como:

discurso ou prática institucional que submeta crianças e adolescentes a procedimentos desnecessários, repetitivos, invasivos, que levem as vítimas ou testemunhas a reviver a situação de violência ou outras situações que gerem sofrimento, estigmatização ou exposição de sua imagem.

Portanto, a escuta deve ser realizada por profissionais capacitados e aptos para o atendimento de crianças e adolescentes com deficiência, visto que o direito ao acesso à justiça 
não pode ser negado a esta parcela da comunidade. $O$ espaço físico também precisa ser adequado às pessoas com mobilidade reduzida ou deficiência física e visual, por exemplo.

Desta forma, mostra-se urgente a representatividade de pessoas com deficiência nos ambientes de decisão e nas três esferas do governo e nos três poderes, tendo em vista que são nestas esferas de poder que são determinadas quais as políticas públicas que serão implementadas em benefício das pessoas com deficiência

Sobre o assunto, tendo em vista que a teoria contratualista que Martha Nussbaum pretende complementar é uma utopia realista ${ }^{6}$, interpretaremos analogicamente o ponto de vista da autora sobre a importância da presença de pessoas com deficiência no contrato social, de maneira que consideramos imprescindível a presença destas pessoas nos centros de poder como forma de garantir e efetivar direitos específicos adequadamente às pessoas com deficiência. Sobre o assunto, Nussbaum esclarece que:

\begin{abstract}
A exclusão de pessoas com deficiência e impedimentos da situação do contrato torna-se ainda mais prejudicial, entretanto, quando levamos em consideração uma surpreendente característica estrutural de todas as teorias do contrato social. A tradição do contrato social associa duas questões a princípio distintas: "por quem são determinados os princípios básicos da sociedade?" e "para quem são determinados os princípios básicos?”. (NUSSBAUM, 2013, p. 20).
\end{abstract}

Desta forma, a aplicação da Lei $n^{\circ}$ 13.431/2017 deve garantir que a escuta realizada tanto mediante o depoimento especial quanto a escuta especializada respeite e reconheça as limitações e necessidades específicas de cada deficiência, almejando sempre evitar ou, ao menos, diminuir a revitimização e garantir de forma integral o acesso à justiça a estas vítimas.

Ocorre que o legislador não incluiu na lei que dispõe sobre o sistema de garantia de direitos (Lei 13.431/2017) as crianças e adolescentes com deficiência, e somente no Decreto 9603/2018, que regulamenta a lei indicada acima trouxe um artigo destinado à acessibilidade, o qual consideramos insuficiente para satisfazer as necessidades específicas de crianças e adolescentes com deficiência no sistema de garantia de direitos, o que será analisado a seguir.

Neste contexto, mostra-se oportuno indicar que o Conselho Nacional de Justiça, mediante a Resolução 230, de 22 de junho de 2016, orienta a adequação dos órgãos do Poder

\footnotetext{
${ }^{6}$ Martha Nussbaum, no livro apresentado neste trabalho (Fronteiras da Justiça) almeja, em linhas gerais, complementar a teoria de justiça como equidade de John Rawls no que tange aos princípios de justiça e a posição original, na qual, dentre outras categorias, as pessoas com deficiência estariam excluídas. Esta exclusão teria como consequência a falta de representação destas pessoas, o que geraria por consequência a ausência de princípios a justiça que os contemplassem. A teoria contratualista elaborada por John Rawls citada, bem como a filosofia política são consideradas por ele uma Utopia Realista pois "amplia o que habitualmente se pensa serem os limites da possibilidade política praticável e, ao fazê-lo, nos reconcilia com a nossa condição política e social" (RAWLS, 2014, p. 19).
} 
Judiciário e de seus órgãos auxiliares a pessoas com deficiência, e dentre outras disposições conceitua no artigo $2^{\circ}$ o que é: discriminação por motivo de deficiência; acessibilidade; barreiras, barreiras urbanísticas, barreiras arquitetônicas, barreiras nos transportes, barreiras nas comunicações e na informação, barreiras atitudinais, barreiras tecnológicas; adaptação razoável; desenho universal; tecnologia assistiva; comunicação; atendente pessoal e acompanhante.

A Resolução 230 do Conselho Nacional de Justiça, portanto, reconhece que a pessoa com deficiência, para que tenha o seu direito de acessibilidade garantido, bem como o de acesso à justiça e à expressão, necessita de ações direcionadas à adaptação do Poder Judiciário e de seus serviços auxiliares a este público.

Consideramos que a Resolução do Conselho Nacional de Justiça apresentada acima, apesar de estar em consonância e em obediência à Convenção Internacional sobre os Direitos das Pessoas com Deficiência e seu Protocolo Facultativo e à Lei Brasileira de Inclusão da Pessoa com Deficiência, não esclarece sobre como a criança e o adolescente com deficiência serão acolhidos no Poder Judiciário.

A crítica levantada acima compreende que a resolução data de 22 de junho de 2016 e que a Lei que reconhece que crianças e adolescentes vítimas ou testemunhas de violência necessitam de procedimentos especiais data de 04 de abril de 2017, portanto, a omissão quanto às especificidades destes sujeitos de direitos em relação ao seu atendimento no Judiciário é compreensível.

O que consideramos incompreensível é o silêncio da Lei 13.431/2017 quanto às especificidades das crianças e adolescentes com deficiência, o que claramente já foi reconhecido, apesar de genericamente, pelo Conselho Nacional de Justiça na Resolução 230 de 2016.

No mesmo sentido, o Decreto $n^{\circ}$ 9.603/2018, responsável pela regulamentação da lei em voga, se refere à criança e a adolescente com deficiência no artigo $6^{\circ}$, de maneira vaga, ao tratar da Acessibilidade, como veremos a seguir:

\footnotetext{
Art. $6^{\circ}$ A acessibilidade aos espaços de atendimento da criança e do adolescente vítima ou testemunha de violência deverá ser garantido por meio de:

I - implementação do desenho universal nos espaços de atendimento a serem construídos;

II - eliminação de barreiras e implementação de estratégias para garantir a plena comunicação de crianças e adolescentes durante o atendimento;

III - adaptações razoáveis nos prédios públicos ou de uso público existentes; e IV - utilização de tecnologias assistivas ou ajudas técnicas, quando necessário.
} 
Sobre as pessoas com deficiência, Diniz considera que "a desvantagem social vivenciada pelas pessoas com deficiência não é uma sentença da natureza, mas o resultado de um movimento discursivo da cultura da normalidade, que descreve os impedimentos corporais como abjetos à vida social” (DINIZ, p. 74, 2009). Desta afirmação, podemos apreender que os espaços públicos não são planejados nem projetados com o objetivo de serem acessíveis e adequados às pessoas com deficiência, em decorrência da cultura de que a eles não cabem os espaços públicos.

Isto reflete na problemática apresentada neste artigo no que tange ao acesso à justiça de pessoas com deficiência, especificamente crianças e adolescentes, tendo em vista que até o mês de abril do ano de 2018 ano não havia legislação que garantisse o direito de acesso à justiça de maneira adequada ao grau de desenvolvimento de vítimas com idade inferior a dezoito anos. Portanto, nosso questionamento é: como estender e adequar esta garantia à crianças e adolescentes com deficiência?

É inegável a mudança positiva trazida pela Lei 13.431/2017, que tem por maior objetivo evitar a revitimização destas vítimas e causar o mínimo de danos possível, em decorrência dos depoimentos realizados. Porém, não podemos esquecer das crianças e adolescentes com deficiência, seja ela física ou mental. Acreditamos que a eles deve ser disponibilizado um tratamento que considere e respeite as limitações específicas de cada um, garantindo assim a efetivação do direito à fala, àqueles que não falam mediante a voz, e sim pela linguagem brasileira de sinais, por exemplo.

Neste trabalho, não pretendemos aprofundar o estudo a respeito das deficiências, suas características e tipos. Por esse motivo, não apresentamos uma solução para a adequação dos espaços e treinamento/formação continuada dos profissionais envolvidos na Escuta Especializada e no Depoimento Especial. Nos preocupamos, portanto, com a análise da legislação e outras normas que, ao serem direcionadas a crianças e adolescentes vítimas de violência, devem dispor sobre a realidade, sobre a existência de crianças e adolescentes com deficiência e, portanto, devem ser assistidos no sistema de garantia de direitos de acordo com as limitações e especificidades de cada deficiência.

O objetivo deste trabalho é, então, lançar a atenção para a adequação dos dois procedimentos de escuta e oitiva de vítimas àqueles com deficiência, considerando que só assim se alcançará a proteção integral e o melhor interesse da criança e do adolescente, 
garantindo assim os direitos fundamentais inerentes a eles, e, sobretudo, a garantia e efetivação da dignidade humana, em procedimentos que antes de vê-los como meios de prova, os considera seres humanos que possuem um fim em si mesmos.

Assim sendo, mostra-se fundamental a mudança cultural no que tange ao olhar direcionado à pessoa com deficiência. Consideramos neste sentido por concordar com o posicionamento de Diniz, no qual afirma que "o reconhecimento do corpo com impedimentos como expressão da diversidade humana é recente e ainda um desafio para as sociedades democráticas e para as políticas públicas” (DINIZ, p. 73, 2009).

Mais sensível e atento às necessidades e particularidades das crianças e adolescentes com deficiência que necessitam transitar pelos órgãos do sistema de garantia de direitos, é a Resolução Conjunta n ${ }^{\circ}$ 01, produzida pelo Conselho Nacional dos Direitos da Criança e do Adolescente - CONANDA e pelo Conselho Nacional dos Direitos da Pessoa Com deficiência - CONADE, de 24 de outubro de 2018, que dispõe sobre as diretrizes para o atendimento de crianças e adolescentes com deficiência.

O CONANDA foi criado pela Lei $\mathrm{n}^{\circ} 8.242$, de 12 de outubro de 1991 e integra o conjunto de atribuições da Presidência da República, sendo um órgão colegiado do Ministério dos Direitos Humanos. Foi previsto no artigo 88 do Estatuto da Criança e do Adolescente, dentre as diretrizes de política de atendimento apresentadas, como pode-se observar no inciso II do artigo citado:

Art. 88. São diretrizes da política de atendimento:

(...)

II - criação de conselhos municipais, estaduais e nacional dos direitos da criança e do adolescente, órgãos deliberativos e controlados em todos os níveis, assegurada a participação popular paritária por meio de organizações representativas, segundo leis federal, estaduais e municipais.

Nos termos da Lei que criou o CONANDA (Lei nº 8.242/1991, art, $2^{\circ}$, I e II), compete ao Conanda: "elaborar as normas gerais da política nacional de atendimento dos direitos da criança e do adolescente, fiscalizando as ações de execução, observadas as linhas de ação e as diretrizes estabelecidas nos arts. 87 e 88 do Estatuto da Criança e do Adolescente".

Dentre os atos de atribuição do Conanda, mediante deliberação com aprovação colegiada, está a produção de Resoluções, marcos normativos que devem ser cumpridos integralmente, pois possuem sintonia com a Constituição Federal e com o Estatuto da Criança e do Adolescente. 
A Resolução conjunta produzida entre o CONANDA e o CONADE dispõe sobre as diretrizes para o atendimento de crianças e adolescentes com deficiência no sistema de garantia de direitos, de forma ampla, bem como trata especificamente da escuta especializada e do depoimento especial.

A Resolução em comento estabelece as diretrizes para o atendimento de crianças e adolescentes com deficiência no sistema de garanta dos direitos da criança e do adolescente mediante vinte e nove incisos do seu artigo $1^{\circ}$. Para este estudo, são imprescindíveis os comentários sobre os incisos XII; XIII e XXVII, o que faremos a seguir.

O inciso XII do artigo primeiro dispõe a respeito do fato de a língua abranger as línguas faladas e de sinais e outras formas de comunicação não falada. Este dispositivo almeja a adequação da escuta qualificada a vítimas com deficiência, considerando que o momento da fala é o crucial para o êxito do procedimento. Para tanto, disciplina que se deve:

Art. $1^{\circ}$

XII. Garantir que a escuta qualificada em todos os espaços e serviços ofertados à criança e ao adolescente, na qual a comunicação dependendo da deficiência deve abranger as línguas, LIBRAS, a visualização de textos, o braile, a comunicação tátil, os caracteres ampliados, os dispositivos de multimídia acessível, assim como a linguagem simples, escrita e oral, os sistemas auditivos e os meios de voz digitalizada e os modos, meios e formatos aumentativos e alternativos de comunicação, inclusive a tecnologia da informação e comunicações acessíveis.

Apreende-se que a Resolução em comento está em consonância com a Lei no 13.431/2017 e objetiva complementá-la, dentre outros assuntos, trazendo as formas de comunicação que devem estar à disposição da vítima com deficiência, o que requer o treinamento/qualificação continuada dos profissionais envolvidos nesses procedimentos, o que é tratado no inciso seguinte, a ser o XIII.

Outro ponto crucial que acertadamente foi incluído na Resolução é o que se refere ao momento da denúncia da violência sofrida, ressaltando, assim, o direito ao acesso à justiça, dispondo no inciso XXVII que se deve:

XXVII. Garantir o acesso das crianças e dos adolescentes com deficiência à denúncia de violência, tendo respeitada a veracidade de seus relatos, como violência sexual, física, psicológica, negligência, abandono, bullying, entre outros; garantindo ainda a continuidade do processo nas instâncias competentes, como, conselho tutelar, delegacia, vara da infância e juventude e outros;

Esta Resolução, que consideramos ser fundamental para a efetivação dos direitos de crianças e adolescentes com deficiência, é o ato normativo mais recente no que tange à 
matéria, e, ao ser interpretada em sintonia com o microssistema de garantia de direitos infanto-juvenis revela-se como genuína caracterização dos princípios consagrados pelo Estatuto da Criança e do Adolescente, pois foi produzida pelo Conanda em conjunto com o CONADE, o que traz à tona a visibilidade dos Conselhos de Direitos da Criança e do Adolescente como órgão indispensável à garantia e efetivação de direitos.

\section{CONCLUSÃO}

Mediante a análise de diversos dispositivos vinculantes, sejam eles Leis, Tratados Internacionais ou Resoluções, este estudo proporcionou a demonstração das normas que regem o acesso à justiça de crianças e adolescentes com deficiência.

É imprescindível um olhar sensível para que o estudo na seara das violências seja bem sucedido. Esta sensibilidade refere-se ao fato de a violência possuir várias faces, e a vítima, muitas particularidades.

Não estamos estudando o acesso à justiça de todas as vítimas. Nos debruçamos nas peculiaridades das vítimas com deficiência, que além disso estão em um momento peculiar de desenvolvimento: estão atravessando a infância ou a adolescência. Estas fases, por si só, são delicadas e merecem uma atenção especial.

Crianças e adolescentes são suscetíveis a violências específicas. Estas violências não são exclusivas a estas vítimas, porém, elas se encontram em posição vulnerável, o que torna: 1) mais fácil cometer violência contra eles e 2) mais difícil a fala sobre a violência sofrida.

Dentre as particularidades específicas destas vítimas (apesar de não exclusivas a elas) é a violência intrafamiliar, que pode ser, dentre outras modalidades, física; psicológica ou sexual. Não podemos deixar de salientar que em casos de violência intrafamiliar a revelação da violência sofrida torna-se mais difícil. O que não quer dizer que a revelação da violência sofrida fora do ambiente familiar seja fácil.

Falar sobre a violência, quando se é a vítima, é sempre algo delicado, difícil e em certos casos, perigoso. Ao romper a barreira do silêncio as vítimas precisam encontrar um ambiente seguro no sistema de garantia de direitos. Este ambiente, os procedimentos e a abordagem realizada pelos profissionais precisa ser, sobretudo, adequado às condições, particularidades e limitações da vítima. 
Neste contexto apresentamos a necessidade de esta adequação levar em consideração não apenas o fato da vítima ser criança ou adolescente. $\mathrm{O}$ olhar deve ir além: é fundamental que vítimas que além de estarem passando pelo período etário da infância e adolescência são deficientes encontrem à sua disposição serviços, profissionais, ambientes e procedimentos que se adequem a esta deficiência.

Neste sentido ao responder o problema de pesquisa proposto concluímos no sentido de que a criança e o adolescente com deficiência estão inseridos nas normas que regem o sistema de garantia de direitos. Porém, consideramos que o que foi alcançado foi a garantia de direitos, e não a sua efetivação.

Reconhecemos que a nível nacional a legislação específica sobre o tema é recente e a sua regulamentação ainda está sendo implementada. Contudo, o princípio da prioridade absoluta resguarda a crianças e adolescentes o direito ao atendimento prioritário, inclusive no que tange às políticas públicas, o que demonstra a urgência com a qual esses direitos devem ser efetivados.

\section{REFERÊNCIAS}

AMIN, Andréa Rodrigues ... [et al]. Curso de direito da criança e do adolescente: aspectos teóricos e práticos. São Paulo, Saraiva Educação, 2018.

BITENCOURT, Luciane Potter. Vitimização secundária infanto-juvenil e violência sexual intrafamiliar: por uma política de redução de danos. Rio de Janeiro: Lumen Juris, 2009.

Convenção sobre os Direitos da Criança. Adotada em Assembleia Geral das Nações Unidas em 20 de novembro de 1989. Disponível em: https://www.unicef.org/brazil/pt/resources_10120.html, acessado em 24 de setembro de 2018.

Decreto Legislativo $\mathrm{n}^{\circ}$ 28, de 14 de setembro de 1990. Aprova o texto da Convenção sobre os direitos da criança. Acessado em 24 de setembro de 2018, disponível em:

http://legis.senado.leg.br/legislacao/DetalhaSigen.action?id=535984.

Decreto Presidencial no 99.710 de 21 de novembro de 1990. Promulga a Convenção sobre os Direitos da Criança. Acessado em 24 de setembro de 2018, disponível em: http://www.planalto.gov.br/ccivil_03/Decreto/1990-1994/D99710.htm.

Decreto Presidencial $n^{\circ}$ 9.603, de 10 de dezembro de 2018. Regulamenta a Lei $\mathbf{n}^{\mathbf{0}} \mathbf{1 3 . 4 3 1}$ de 4 de abril de 2017, que estabelece o sistema de garantia de direitos da criança e do adolescente vítima ou testemunha de violência. 
DINIZ, Debora; BARBOSA, Lívia e DOS SANTOS, Wederson Rufino. Deficiência, direitos humanos e justiça. SUR Revista internacional de direitos humanos. São Paulo, n.11, v.6, p. 65-77, dez. 2009.

KANT, Immanuel. Fundamentação da metafísica dos costumes. Tradução de Paulo Quintela. Lisboa: Edições 70, 1995. (Textos filosóficos).

Lei $\mathrm{n}^{\mathbf{o}} 8.242$, de 12 de outubro de 1991. Cria o conselho Nacional dos Direitos da Criança e do Adolescente (Conanda) e dá outras providências.

Lei $\mathrm{n}^{\mathbf{0}}$ 13.431, de 04 de abril de 2017. Estabelece o sistema de garantia de direitos da criança e do adolescente vítima ou testemunha de violência.

LUCIANE, Potter; HOFFMEISTER, Marleci V. Depoimento especial de crianças e adolescentes: quando a interdisciplinariedade aproxima os olhares. Porto Alegre: Livraria do advogado, 2016.

NUSSBAUM, Martha C. Fronteiras da justiça: deficiência, nacionalidade, pertencimento à espécie. São Paulo: Martins Fontes, 2013.

RAWLS, John. A lei dos povos e a ideia de razão púbica revisitada. Lisboa. Edições 70, 2014.

Resolução no 10 de 29 de junho de 2010 do Conselho Federal de Psicologia. Institui a regulamentação da escuta psicológica de crianças e adolescentes envolvidos em situação de violência, na rede de proteção. Acessado em 24 de setembro de 2018, disponível em: http://site.cfp.org.br/wp-content/uploads/2010/07/resolucao2010_010.pdf

Resolução no 33 de 23 de novembro de 2010 do Conselho Nacional de Justiça. Recomenda aos tribunais a criação de serviços especializados para a escuta de crianças e adolescentes vítimas ou testemunhas de violência nos processos judiciais. Depoimento especial.

Resolução n 230 de 22 de junho de 2016 do Conselho Nacional de Justiça. Orienta a adequação das atividades dos órgãos do Poder Judiciário e de seus serviços auxiliares às determinações exaradas pela Convenção Internacional sobre os Direitos das Pessoas com Deficiência e seu Protocolo Facultativo e pela lei Brasileira de Inclusão da Pessoa com Deficiência por meio - entre outras medidas - da convolação em resolução da Recomendação CNJ 27, de 16/12/2009, bem como da instituição de Comissões Permanentes de Acessibilidade e Inclusão. Acessado em 12 de dezembro de 2018. Disponível em: http://www.planalto.gov.br/ccivil_03/_Ato20152018/2018/Decreto/D9603.htm. 